\title{
A POIÊTIKÊ TECHNÊ COMO INSTRUMENTO META-FILOSÓFICO
}

\author{
Humberto Brito* \\ hbrito@fcsh.unl.pt
}

RESUMO Defendo que o estudo de Aristóteles sobre poiêtikê technê deve ser entendido como um estudo sobre um vocabulário meta-filosófico. Defendo ainda que a sua vantagem principal é a de tornar explícita uma contiguidade conceptual entre um conjunto de problemas relacionados com teoria da acção, racionalidade e cognição colectiva, assim como a de dar inteligibilidade indirecta à partilha de disposições em comunidades humanas.

Palavras-chave Catarse, mimese, racionalidade, acção, inteligibilidade

ABSTRACT I will argue that Aristotle's inquiry into poiêtikê technê should be taken as an inquiry into a meta-philosophical vocabulary. I claim that the main advantage of such a vocabulary is that of making explicit a conceptual contiguity between a number of problems concerning action theory, rationality, collective cognition, as well as that of affording indirect intelligibility to how human communities share dispositions.

Keywords Catharsis, mimesis, rationality, action, intelligibility

I.

Os comentadores da Poética sempre se mostraram fascinados pela

* Investigador de Pós-doutoramento e coordenador da Rede de Filosofia e Literatura na Universidade Nova de Lisboa. Artigo recebido em 9/11/2010 e aprovado em 15/6/2011.

KRITERION, Belo Horizonte, $n^{\circ}$ 125, Jun./2012, p. 41-58. 
observação misteriosa e quase apócrifa de Aristóteles a respeito da catarse, ${ }^{1}$ polarizando o debate sobre a Poética em torno de versões mais ou menos opostas da função meliorativa da tragédia. Habituámo-nos pois a esperar uma espécie de apologia da poesia e deixámos de ser capazes de ler o tratado a não ser em relação a tal pano de fundo. Salvo raríssimas excepções, toda uma longa história de dissensão é prova aliás da larga unanimidade entre os comentadores acerca do ponto geral da Poética. De Castelvetro a Lear, somos unânimes em discordar de entre um conjunto de configurações rivais de uma teoria geral da catarse. Qualquer teoria da catarse (como, de facto, qualquer teoria da mimesis trágica) deve, no entanto, explicar a relação causal que não pode deixar de haver entre tragédias e pessoas, de modo a que uma reacção partilhada possa verificar-se de todo. E essa relação causal é normalmente dada por adquirida sem quaisquer outras explicações. ${ }^{2}$

Sem dúvida que Aristóteles constrói todo o seu argumento sobre a tragédia na suposição geral de que tal ligação existe. No entanto, compreenderemos melhor o que está em causa se contrastarmos o naturalismo de senso comum por detrás dessa suposição contra a noção (de origem Renascentista) de que a tragédia aristotélica 'tem' um efeito meliorativo universalizável, e de que a katharsis é o resultado padrão necessário produzido por tragédias perfeitas. Embora nenhum comentador se atreva a ir tão longe quanto G.E. Lessing (para quem a Poética seria tão infalível quanto os Elementos de Euclides), ${ }^{3}$ a presunção de uma causalidade necessária, parecida com uma lei natural, está caracteristicamente presente nas leituras do texto de Aristóteles desde as suas primeiras traduções modernas. ${ }^{4}$ Ao contrário da maioria dos seus leitores modernos, no entanto, Aristóteles não chega a propor tal ideia: "A tragédia, então, é a imitação de uma acção ... com incidentes que provocam temor e piedade, mediante os quais é produzida a catarse de tais emoções". ${ }^{5}$ Ora, de 'A causa B' não se segue que 'A causa B necessariamente'.

1 Po. 1449 b28.

2 Negligenciar este aspecto conduziu a maioria dos comentadores na tradição de estudos sobre a Poética a adoptar, mais ou menos explicitamente, versões, a meu ver, pouco apelativas da psicologia moral. Em Pessoas como Nós: Uma discussão da Poética de Aristóteles (2007) (http://www.fl.ul.pt/posgraduados/ teoria literatura/Brito2.pdf) discuto este problema em maior detalhe.

3 Lessing, Hamburgische Dramaturgie (1767), Dramaturgia de Hamburgo, Selecção Antológica, tradução de Manuela Nunes, Fundação Calouste Gulbenkian, Lisboa, 2005, p. 179.

4 Sobre debate em torno da catarse aristotélica no Cinquecento, ver: Weinberg, A History of Literary Criticism in the Italian Renaissance, vol. I (1961), Halliwell, The Aesthetics of Mimesis, Ancient Texts and Modern Problems, 2002; Belfiore Tragic Pleasures: Aristotle on Plot and Emotion, 1992, Javitch "On the Rise of Genre specific Poetics in the Sixteenth Century" (2001),

5 Po. 1449b25-28. Usarei a tradução portuguesa da Poética de A. M. a Valente (2004) como referência, modificando-a ocasionalmente. Cito aqui apenas um excerto da definição de tragédia oferecida por Aristóteles na Poética 6. 
A noção de que 'A causa B necessariamente' subjaz àquilo que descreverei de seguida, de uma maneira, receio, excessivamente esquemática, como a configuração das leituras habituais dos capítulos 4 e 9 da Poética. Estes capítulos são quase sempre lidos reciprocamente e de acordo com um raciocínio cuja paráfrase mais simplificada poderia ter o aspecto da seguinte lista de manobras. Em geral, (1) as pessoas gostam de aprender (manthanein) e admirar coisas (thaumazein); ${ }^{6}$ e, em particular, tal como Aristóteles insiste na Retórica, (2) elas têm prazer naquilo que aprendem e que são levadas a perceber através do contacto com imitações: nas suas palavras, manthanein kai sullogizesthai. ${ }^{7}$ (3) Num sentido minimal, nisso consiste, então, o prazer que a poesia lhes dá. ${ }^{8}$ Ora, uma vez que a poesia de algum modo representa o universal, ta kathoulou, ${ }^{9}$ (4) o que aprendemos com a tragédia será, pois, universal nalgum sentido. Assim, (5) se a catarse está ligada ao prazer próprio da tragédia e é o efeito necessário, o fim último, se quisermos, do tipo perfeito de enredos trágicos (o que melhor 'representa' o universal), então (6) a catarse está ligada à 'transmissão' (i.e. à revelação ou clarificação $)^{10}$ de alguma coisa universal nalgum sentido, e.g. certa verdade geral acerca da 'condição humana'. Por analogia com as recomendações de Aristóteles na parte final da Política acerca dos benefícios de formas entretenimento musical, ${ }^{11}$ sugere-se, nesse sentido, que (7) assistir a boas tragédias permite que os espectadores treinem as suas emoções e aptidões intelectuais e morais, o que os prepara para a vida moral "sorvendo o sumo sem morder a casca", ${ }^{12}$ para usar uma metáfora adequada de Gerald Else. (8)

6 Po. 1448b14; Ret. 1371a20 ff; Met. 980a1.

7 Po.1448b15ff, Ret. $1371 \mathrm{b9}$

8 Po. 1448 b9-14

9 Po. 1451b5-10

10 A teoria da catarse aristotélica entendida como "clarificação" - na realidade, como Aufklärung (Brito, op. cit. 2007: p. 105) - é defendida por Leon Golden numa série de ensaios cuja enorme influência moldou os estudos sobre a Poética na segunda metade do séc. XX. (Golden, "Catharsis", TPAPA, vol. 93, 1962, pp. 5160. "Mimesis and Katharsis", Classical Philology, vol. 64, No. 3, 1969, pp. 145-153. "The Purgation Theory of Catharsis", The Journal of Aesthetics and Art Criticism, Vol. 31, No. 4, 1973, p. 473. "The Clarification Theory of Catharsis", Hermes, 104, 1976, pp. 437-52. "Katharsis as Clarification: An Objection Answered", The Classical Quarterly, New Series, vol. 23, No. 1, 1973. "Toward a Definition of Tragedy", The Classical Journal, vol. 72 , No. 1, 1972). Sobre a influência exercida pela teoria de Golden, ver Belfiore: "Aristotle on Tragic and Comic Mimesis", Bryn Mawr Classical Review, http://ccat.sas.upenn.edu/bmcr/1993/04.01.12.html, 2004.

11 Pol. $1342^{\mathrm{a}} 18$

12 Else, Gerald. Aristotle's Poetics: the Argument, Cambridge: Harvard University Press, 1957, p. 451. O nome de Else é hoje raramente mencionado, embora o esquema padrão que acabo de descrever tenha origem numa descoberta filológica. Segundo Else, salvo, talvez, a referência à catarse, todos os elementos da definição de tragédia no capítulo 6 (1449b25) tinham sido introduzidos por Aristóteles nos capítulos anteriores da Poética, o que tornaria a definição de tragédia num sumário lógico do argumento dos capítulos 1-5. Esta descoberta é por vezes erradamente atribuída a Golden (por exemplo, Nussbaum comete este erro em The Fragility of Goodness: Luck and Tragedy on Greek Tragedy and Philosophy, 1986, Cambridge: Cambridge University Press, 2001, pp. 388). Corrigindo Else, Golden sugere que tal referência à catarse é precedida, ainda no capítulo 4, pelas passagens acima citadas (Po. 1448b9ff). Para explicitar 
Por outro lado, talvez seja esse o caso ainda que, como observou Lear, os espectadores de tragédias que Aristóteles tinha em mente já estivessem para lá da necessidade ou mesmo da possibilidade de qualquer treino moral $;{ }^{13}$ e nesse caso não-morder-a-casca significa apenas que, na tragédia, "A vida é vivida em pleno, imaginariamente, mas sem arriscarmos seja o que for". ${ }^{14}$

A família de interpretações do capítulo 9 da Poética a que pertence a proposta de Lear de que a mimese nos permite experimentar possibilidades "fora do plano comum" (tal como o "alívio de 'descarregar' [certas] emoções num ambiente seguro") ${ }^{15}$ dá uma inflexão modal à famosa distinção de Aristóteles entre poesia e história, como se ficção fosse realmente apenas aquilo que está em causa. Tal distinção ${ }^{16}$ tem menos que ver com ficção, ou apenas com ficção, no entanto, do meu ponto de vista, do que com o que Aristóteles entenderia por representação de carácter, èthos. Por outras palavras, tem que ver com o género de unidade de carácter que uma boa tragédia permite representar. A poesia representa 'universais' e a história 'particulares'; mas por "universal" entende-se "aquilo que certa pessoa dirá ou fará, de acordo com a verosimilhança ou a necessidade", ${ }^{17}$ formulação que reitera os critérios adoptados por Aristóteles na definição de carácter no capítulo 6. "Carácter", explica Aristóteles, "é o que revela qual a decisão [prohairesis], como naqueles casos em que a escolha não é óbvia, e, por isso, não exprimem carácter as palavras nas quais quem fala não aceita nem recusa coisa alguma". ${ }^{18}$ Para Aristóteles, o êthos emerge nas escolhas tornadas evidentes pelas acções de pessoas, pelo que escolhem dizer ou não dizer, pelo que escolhem fazer ou não, e tais escolhas, tais palavras, tais acções, emergem sempre, como nos é também explicado na Ética a Nicómaco, como próprias de um 'género de' (hoios) pessoa:19 a "tragédia é a imitação de uma acção e, através desta, principalmente, dos agentes" ${ }^{20} \mathrm{O}$ único lado 'universal' daquilo

o sentido em que tais passagens são precedente explicativo da chamada Katharsisfrage na definição de tragédia, Golden sugere que se comece por ler os capítulos 4 e 9 da Poética em conjunto. (Golden, "Catharsis", TPAPA, vol. 93, 1962, pp. 51-60.)

13 Lear, Jonathan. "Catharsis", Essays on Aristotle's Poetics, ed. A.O, Rorty. Princeton University Press: New Jersey, 1992, pp. 319-320.

14 Lear, idem, p. 334.

15 Lear, ibid, p. 334.

16 A saber, a de que "a poesia é mais filosófica e tem um carácter mais elevado que a História" pois esta "relata o que aconteceu", tratando o particular, e aquela "o que poderia acontecer", e por isso "expressa o universal". Po. $1451 \mathrm{~b} 5$.

17 Po. $1451 \mathrm{~b} 7$.

18 Po. $1450 \mathrm{~b} 9$.

19 EN 1120a31, 1146a6, 12, 32.

20 Po. 1450b4, itálico meu. Adopto aqui a tradução de Bywater (De Poetica, The Basic Works of Aristotle, ed. McKeon, Random House: New York, 1941), para sublinhar o peso atribuído por Aristóteles a agentes. Valente traduz "dos homens que actuam". 
que a poesia representa ("aquilo que certa pessoa dirá ou fará, de acordo com a verosimilhança ou a necessidade") ${ }^{21}$ é que, por assim dizer, na maior parte dos casos, 'este género de pessoa age assim e assim'.

Por outro lado, Aristóteles esclarece que "a tragédia não é a imitação dos homens, mas das acções e da vida", da "felicidade e infelicidade", que está nas acções e não nas qualidades das pessoas. O carácter é uma "qualidade" (poios) dos personagens mas não é isso que os torna felizes ou infelizes: o que os torna felizes ou infelizes são as suas $a c c ̧ o ̃ e s .{ }^{22}$ (E.g. mesmo a pessoa prudente pode errar e ser infeliz.) O principal objectivo da tragédia é, por isso, o de representar a estrutura das acções adequadamente, ou melhor, o de representar adequadamente a estrutura de um certo tipo de acções: acções nas quais uma pessoa cai em desgraça por um erro próprio ${ }^{23}$ (hamartia). Por outras palavras, o objectivo da tragédia não é o de imitar pessoas, mas a tragédia representa pessoas enquanto agentes, e, apenas enquanto agentes, pessoas com determinadas qualidades. É por isso que "os caracteres são abrangidos pelas acções", ${ }^{24}$ o que também significa, no entanto, que uma mera escolha isolada não nos dá acesso ao 'género de' agente, ao carácter, de certa personagem. É preciso uma acção completa (uma acção capturada sob uma narrativa racional e verosímil) para que as qualidades do agente se tornem inteligíveis, para que se perceba que este ou aquele 'género de' agente age coerentemente assim e assim. ${ }^{25}$ Até mesmo os caracteres incoerentes (como e.g. a Ifigénia de Eurípides, da Ifigénia em Áulide, diz-nos Aristóteles) devem pois ser representados, de acordo com o princípio geral de verosimilhança e necessidade, como "coerentemente incoerentes". ${ }^{26}$ Tal apenas se obtém mediante a unidade de acção conseguida por um enredo (mythos) adequado, e é por esta razão que "o enredo é (...) o princípio e como que a alma da tragédia". ${ }^{27}$

Em suma, a inflexão modal habitualmente adoptada na interpretação da distinção entre poesia e história, tornando-a numa questão de distinguir entre ficção e não-ficção, e, em última análise, numa discussão sobre os benefícios de actividades relacionadas com ficção (o assunto central de qualquer teoria da catarse), perde de vista o ponto filosófico talvez mais interessante: o de 
'como dar inteligibilidade a caracteres?', i.e. como dar inteligibilidade a que 'géneros' de agentes, na maior parte dos casos, agem 'assim e assim'. A resposta de Aristóteles é a de que um certo tipo de narrativas se oferece como recurso técnico mais adequado para dar inteligibilidade à existência 'de géneros' de agentes, um tipo de narrativas que se caracteriza por respeitar certos princípios técnicos, que lhes confere uma unidade de sentido alcançada "sem explicação verbal"28 e em relação à qual se verifica, por outro lado, uma reacção partilhada. O longo debate sobre a Poética desde o Renascimento entende-a, em geral, como uma tentativa de Aristóteles de responder à pergunta: 'Como produzir uma certa reacção partilhada?', na suposição de que tal efeito da tragédia seria benéfico a uma escala comunitária. Uma poiêtikê technê teria pois uma função ética e mesmo política. Do ponto de vista que estou a tentar descrever, a função da poiêtikê technê é, por contraste, a de um vocabulário puramente conceptual sob o qual várias questões normalmente desligadas entre si podem ser descritas num mesmo plano, numa continuidade. Por exemplo, tal vocabulário permite descrever no mesmo plano explicativo a existência de uma convergência ou uma partilha de reacções morais em relação a certas coisas, o reconhecimento partilhado de certas possibilidades, e ainda as causas (a explicação) dessa partilha de reacções. Podemos assim admitir que uma poiêtikê technê (como explicação para uma partilha de reacções) constitui também um modo indirecto de dar inteligibilidade à existência de um ethos comum em comunidades humanas. Nas secções seguintes tentarei explicar porquê.

\section{II.}

$\mathrm{Na}$ secção anterior vimos as razões pelas quais Aristóteles considera o enredo (mythos) como que a alma da tragédia. Na sua opinião, a melhor espécie de tragédia é ainda aquela em que "tudo é peripécia e reconhecimento"29 (i.e. ‘tudo' o que importa). ${ }^{30}$ É então como se o reconhecimento-com-peripécia fosse a alma do enredo: a minha primeira tarefa nesta secção será a de tentar explicitar esta ideia, começando pelos princípios mais básicos.

$\mathrm{O}$ reconhecimento, anagnorisis, é a "passagem da ignorância para o conhecimento" 31 associada por Aristóteles ao cerne de todo o enredo: metabolê, 
a mudança que separa o nó (desis) de um desenlace (lysis). ${ }^{32}$ Todo o argumento da Poética parece ser orientado por tentativas de explicitar esta 'mudança', que é ao mesmo tempo a distinção mais panorâmica e geral feita a respeito de enredos. Numa boa tragédia, tal corresponde a uma viragem da felicidade para a infelicidade dos caracteres produzida por uma "mudança dos acontecimentos para o seu reverso", a que Aristóteles dá a designação técnica de peripécia, peripeteia. ${ }^{33}$ A peripécia, viragem que abre o desenlace, deve já resultar do próprio nó, em vez de surgir ex machina, defende Aristóteles, para quem a estipulatividade injustificada de certas soluções narrativas é uma forma de irracionalidade própria apenas de "maus poetas". ${ }^{34}$ De preferência, "Não deve haver nas tragédias nada de irracional, e, se houver, que seja fora da tragédia, como no Édipo de Sófocles", ${ }^{35}$ esclarece a propósito, dando como exemplos de o que entende por irracional (alogon) certos gestos típicos de estipulação autoral ou ex machina mediante os quais se torna muito conspícua a falta de ligação explicativa, na cadeia dos acontecimentos, entre nó e desenlace. ${ }^{36}$ Não apenas a peripécia deve resultar do enredo, mas também o reconhecimento (que pode ou não acompanhar tal peripécia no desenlace, e que pode ou não estar ligado a ela, caso a acompanhe), também o reconhecimento deve nascer da peripécia, e, portanto, na melhor das hipóteses, deve decorrer do próprio enredo. Do ponto de vista de Aristóteles, a cadeia de acontecimentos gerada pela mudança deve, de acordo com um princípio de verosimilhança e necessidade, como uma cadeia de inferências bem formada, levar à cena de reconhecimento.

O exemplo perfeito e clássico deste género de encadeamento, a que chama "tragédia complexa", é para Aristóteles o da ligação entre o reconhecimento de Édipo, na tragédia de Sófocles, e a cena na qual "o mensageiro que chega com a intenção de [o] alegrar (...) e de o libertar dos seus receios em relação

32 Nó, desis, i.e. "os factos exteriores à acção e alguns dos que constituem essa acção" ou "o que vai desde o princípio até ao momento imediatamente antes da mudança"; desenlace, lysis, i.e. "o que vai desde o início desta mudança até ao fim", Po. 1455b27-29.

33 Po. $1452 \mathrm{a} 22$

34 Po. $1451 \mathrm{~b} 35$

35 Po. 1454 b6

36 Aristóteles dá-nos, a este respeito, vários exemplos de estipulatividade gratuita, uma forma de estupidez técnica presente em cenas de peripécia ex machina (Po. 1454a36-1454b5) e certos tipos inadequados de reconhecimento (Po. 1454b20-1455a15), todos eles, em última análise, 'forjados pelo poeta' (Po. 1454b31). Nesses casos, o poeta mostra-se incapaz de produzir uma explicação racional verosímil para a relação entre nó e desenlace, o que o leva a estipular uma solução. Em tais casos temos afinal "o que o poeta quer, mas não o que o enredo requer" (1454b35), sendo por isso que, como nos é dito num dos elogios a Homero, "o poeta em si deve dizer o menos possível, pois não é através disso que se faz a imitação" (Po. 1460ª 7). Quando a estupidez do poeta se faz notar, isso dificulta o efeito da tragédia, uma vez que "o espantoso" deve surgir "no meio de factos verosímeis" (Po. 1455a16). 
à mãe, (...) [produz] o efeito contrário", ${ }^{37}$ gerando uma cadeia de revelações que leva Édipo a compreender que é o causador involuntário da sua própria desgraça. A par do reconhecimento de Édipo o reconhecimento mais ou menos simultâneo ${ }^{38}$ das causas da acção por parte dos espectadores, e o espanto associado a esta nova percepção da acção como um todo (alcançado "sem explicação verbal"), ${ }^{39}$ parecem estar ligados à produção das emoções a cuja 'remoção' ou 'extravasamento', para facilitar, chamamos catarse. Aristóteles observa que as emoções de "temor e compaixão (...) são muito [mais] facilmente suscitadas quando se processam contra a nossa expectativa, por uma relação de causalidade entre si. Desta forma," continua, "a imitação será mais surpreendente do que se surgisse do acaso e da sorte, pois os factos acidentais causam mais admiração quando parece que acontecem de propósito". ${ }^{40}$

É interessante que, para delimitar e explicitar o aspecto das tragédias no centro das suas atenções, i.e. o que se passa na 'mudança', Aristóteles recorra na Poética à mesma analogia que usa de passagem na Metafísica para sugerir que quando "uma dificuldade no nosso pensamento aponta para um 'nó no objecto", superar essa dificuldade é como "desatar um nó". ${ }^{41} \mathrm{Na}$ Poética, Aristóteles não se cansa de tentar capturar a intuição de fundo de que a representação de um certo tipo de cenas de reconhecimento 'produz' ou está ligada à experiência de libertação de uma sobrecarga emocional, gerada nos espectadores por aquilo que poderíamos descrever como as suas expectativas mais ou menos difusas acerca da violação de certos laços cometida na ignorância (o objecto do erro do herói, hamartia: tipicamente, a causa da sua queda em desgraça. Parece haver uma ligação estreita entre as nossas expectativas sobre esse erro, que são primeiro geradas e depois confirmadas pela própria acção, e as expectativas difusas do próprio herói a esse respeito. Os "receios [de Édipo] em relação à mãe"42 não apenas não são no vazio como são basicamente os mesmos que os de qualquer espectador comum. É sobre essas expectativas que se formam as emoções dos espectadores.) Não nos devemos esquecer, por outro lado, de uma suposição mais geral de Aristóteles, para a qual Jonathan Lear também nos chama a atenção, ${ }^{43}$ de que, tal como a actividade do professor 
se opera nos alunos, a actividade do poeta se opera "nalgum paciente - não ocorre desligada de um sujeito, sendo de A sobre B". ${ }^{44}$ Quer dizer, a agência do poeta opera-se naqueles sobre os quais a sua actividade recai: na paciência dos espectadores, por assim dizer. Muito a propósito, Aristóteles observa, no capítulo 24, que um dos talentos de Homero era nada menos que o de conduzir "as nossas mentes" a inferências erróneas, ${ }^{45}$ nomeadamente em cenas de reconhecimento inadequadas baseadas "num falso raciocínio do público". ${ }^{46}$ Segue-se então, talvez, que as cenas de reconhecimento adequadas devem basear-se, podemos supor, num raciocínio correcto por parte do público. E tal como as emoções suscitadas pela acção, também esse raciocínio tem de nascer sobre as expectativas formadas nos espectadores ao longo da acção. Há uma cadeia inferencial bem formada nas suas emoções. Não é um acidente que as suas piores expectativas se verifiquem; não é sem razão que sentem medo e piedade.

Por outro lado, não se segue, porém, que tal reacção seja necessariamente partilhada por todos os espectadores, que seja um efeito necessário de uma boa tragédia. (Aristóteles explica-nos na Retórica que nem todas as pessoas são capazes de sentir as emoções suscitadas por tragédias; ${ }^{47}$ por definição, não haverá 'catarse' para aqueles que não sentem coisa alguma). Tradicionalmente, dá-se por adquirido que a relação entre a acção trágica e as reacções de espectadores é uma relação causal necessária, automática, universal. Todavia, jamais se tentou caracterizar essa relação, que me parece tudo menos necessária. Com efeito, Aristóteles parece sugerir-nos que tal relação se estabelece mediante uma ponte inferencial. "O espectador faz inferências (sullogismos)", tal como explica na Retórica, ${ }^{48}$ parafraseando uma passagem do capítulo 4 da Poética, a que já aludi (e em torno da qual a dissensão é enorme), na qual nos diz que a razão pela qual as pessoas têm prazer em imitações "É que [elas], quando vêm as imagens, gostam dessa imitação, pois acontece que, vendo, aprendem e deduzem o que representa cada uma, por exemplo, 'este é aquele assim e assim""49 - ou como Stephen Halliwell demonstrou: "que aquele homem ali é assim e assim". .0

44 Fís. III.3 $202 \mathrm{~b} 5$

45 Po. $1460 a 25$.

46 Po. $1455 a 13$.

47 Ret. 1385b19-21

48 Ret. 1371 b9.

49 Po. $1448 \mathrm{~b} 15 \mathrm{ff}$.

50 Halliwell, "Aristotelian Mimesis and Human Understanding", Ø. Andersen and J. Haarberg (ed.), Making Sense of Aristotle: Essays in Poetics, London: Duckworth, 2001, 87-107. 
Dizer que "aquele homem ali é assim e assim" é possivelmente um modo abreviado de Aristóteles se referir, tal como tentei explicar na secção anterior, a uma revelação da inteligibilidade de um carácter, i.e. um 'género de' agente que, na maior parte das vezes, age 'assim e assim', revelação conseguida mediante uma representação da acção de acordo com o que é necessário ou o que acontece na maior parte das vezes. A revelação produzida pelo reconhecimento dos espectadores (i.e. pelas inferências aduzidas a respeito das causas da acção, que se encadeiam num scorekeeping contemplativo, para usar uma expressão de Brandom) leva-os a apreender (ou representar) a acção de uma tragédia como um todo causal unificado, ao mesmo tempo que o "nó" no objecto se desenlaça, para continuar a usar a metáfora de Aristóteles. Que "aduzir inferências" se pareça com "uma espécie de alívio ou uma sensação de chegada" (407a32), como nos é dito em De Anima, sugere que há uma espécie de experiência de satisfação ou aprazimento inferencial associada à remoção da dor suscitada pelo "nó" no objecto. Talvez seja a isto que os comentadores se referem quando descrevem um ‘prazer cognitivo' a propósito da posição de Aristóteles no capítulo 4 da Poética. Por outro lado, o scorekeeping extático que viabiliza nos contempladores a inteligibilidade anagnorética da acção trágica em causa - por palavras menos cerimoniosas, a atenção que nos agarra àquela tragédia -, não pode estar desligado da nossa psicologia moral: não há propriamente inferências frias para Aristóteles, mas antes tudo ao mesmo tempo. Se é que precisamos de descrever aquilo a que ele se refere por catarse na Poética, tal não poderá ser concebido como extravasamento ou alívio a não ser como o prazer associado a um extravasamento ou a um alívio da experiência de tudo ao mesmo tempo: espanto (thaumaston), temor, compaixão, elevação moral. No entanto, para o que nos importa, não será necessário caracterizar a fundo a psicologia de tal experiência.

Bastaria talvez sublinhar que tal género de experiência é associado por Aristóteles a um reconhecimento por parte dos espectadores de uma boa tragédia, um reconhecimento que revela as causas de uma certa acção e desse modo clarifica as suas expectativas difusas a respeito dessas causas, através de um fechamento explicativo, por assim dizer. ${ }^{51}$ Aristóteles parece partir do princípio de que um fechamento de sentido (por outras palavras: encontrarmos uma explicação para acidentes bizarros) alivia a sobrecarga emocional que acompanha a indefinição de tais expectativas. ${ }^{52}$ Por outro lado, mediante este

51 Este fechamento é talvez facilitado por um enredo cuja dimensão possa ser "abrangida por um só olhar", como uma totalidade, como no caso de um animal belo (Po. 1450b34-1451a12).

52 Não há expectativas no vazio: no caso da tragédia, temos expectativas acerca de desgraças poderem acontecer a pessoas "que se assemelham a nós" e não merecem "a desdita" (o que nos enche de temor 
fechamento explicativo, a acção unifica-se como uma totalidade, conferindo inteligibilidade ao carácter, èthos, de uma personagem, permitindo que os espectadores o apreendam como próprio de um 'género de' pessoa: "aquele homem ali é 'assim e assim"' (houtos ekeinos).

Mais uma vez, por 'género de' pessoa entenda-se caracteres que se distinguem por exibirem certas qualidades morais dominantes, como tenho vindo a sugerir, e tal como Aristóteles os parece entender na Ética a Nicómaco, onde recorre a um procedimento explicativo tecnicamente paralelo àquele que estuda na Poética. Ao dar inteligibilidade a caracteres mediante uma personificação de qualidades de carácter (o indivíduo megalópsico, o indivíduo acrático, etc.), Aristóteles obedece a um princípio de narratividade explicativa mediante o qual tal ou tal qualidade apenas se mostra sob uma descrição verosímil das acções próprias (ou da relação entre as acções) de quem possui uma dada qualidade, no contexto de $u m a$ vida. ${ }^{53}$ Tal procedimento encontra numa discussão da tragédia a hipótese prometedora de, sob um certo tipo de descrição, ou sob um certo tipo de mythos, certas qualidades de carácter serem imediatamente claras para a grande maioria dos espectadores, independentemente de diferenças de opinião ou independentemente da sua relativa sofisticação intelectual. ${ }^{54}$ (Para Aristóteles é aliás como se linguagem de mais atrapalhasse o género de fechamento explicativo em questão. ${ }^{55}$ Não é que o efeito da tragédia se reduza à revelação de uma unidade de carácter imediatamente reconhecível pela maioria das pessoas (e não necessariamente por todas), mas antes que as razões do sofrimento do herói são partilhadas, i.e. aceites implicitamente como boas razões ou se quisermos como as razões do sofrimento esperável de alguém na sua situação. Uso aqui a expressão 'aceites implicitamente' uma vez que a única face desta reacção partilhada são possivelmente os sinais externos, nem sempre presentes, de um género de comoção tão comum que dispensa descrição, e a que nos habituámos a dar o nome 'catarse'. (Certamente, ninguém precisa de pedir uma segunda opinião sobre a razão de ser das emoções que uma tragédia lhe desperta: em parte, porque não há tempo para isso, em parte porque seria estúpido e escusado.) A questão é que seja isso o que for, para Aristóteles

e compaixão), embora sejam os causadores involuntários da sua própria desgraça (o que nos enche de espanto).

53 Ver A. Maclntyre, After Virtue, A study in moral theory (1985), Duckworth: Londres (2003), capítulos 12 e 15. 54 Po. 1448 b14.

55 Os "efeitos de compaixão, temor, grandiosidade, ou verosimilhança (...) devem ser revelados sem explicação verbal” (Po. 1456b4). A lexis tem de ser clara sem ser banal, sendo um elemento indissociável do género trágico, mas relativamente acessório no que respeita à sua função. 
tal emerge ao mesmo tempo que a nobreza de carácter (própria da "acção elevada") ${ }^{56}$ daqueles sobre cujo sofrimento é a compaixão dos espectadores, e cuja desgraça sob as próprias mãos, na ignorância, os enche de medo. E tal depende de estes reconhecerem o carácter do herói não apenas como "bom", mas ainda "apropriado à personagem", "semelhante a nós" (pois é isso que gera a compaixão e o temor $)^{57} \mathrm{e}$, num sentido particular, semelhante a si mesmo: ele deve ser representado com uma coerência tal que respeite um princípio de verosimilhança e necessidade. Em suma, para Aristóteles a poesia enche-nos de coisas - coisas agradáveis e dolorosas (o que é "gerado pelos acontecimentos" $)^{58}$ - e, a haver lugar a um extravasamento ou alívio, tal não se desliga de um certo fechamento de sentido, de um "raciocínio do público", 59 como a percepção de que "Aquele homem ali é 'assim e assim"” (houtos ekeinos). ${ }^{60}$

\section{III.}

A razão pela qual Aristóteles não explica o que quer dizer com 'catarse' na Poética - um lapso tão incaracterístico que facilmente o confundimos com um facto filológico - é possivelmente a de que não é realmente importante descrever a fundo a psicologia da catarse (e muito menos a sociologia ou a

56 Po. 1449 b24.

57 Retórica, II.5; II.8.

58 Po. 1453 b14.

59 Po. $1455 a 13$.

60 Stephen Halliwell oferece-nos, todavia, uma explicação bem diferente do uso de "houtos ekeinos" por Aristóteles no capítulo 4 da Poética (Halliwell, "Aristotelian Mimesis and Human Understanding", Making Sense of Aristotle, Essays in Poetics", ed. Andersen \& Harberg, Duckworth: London, 2001, p. 90). Segundo Halliwell, no contexto gramatical em questão "houtos ekeinos" pode apenas fazer referência a indivíduos e não a tipos: não a 'géneros de'. Poderíamos talvez responder, no entanto, que a percepção de semelhanças qua semelhanças de algum modo presume um certo grau de generalidade conceptual. Embora apenas se possa aplicar a indivíduos, nada nos impede de admitir que "houtos ekeinos" se aplica ao reconhecimento de indivíduos como pertencendo a 'géneros de' pessoa, cujas qualidades são 'assim e assim', ou cujas acções e decisões são próprias de pessoas 'assim e assim', etc. Halliwell observa ainda, por outro lado, que nesta passagem o que Aristóteles tem em mente só pode ser a identificação de figuras humanas em imagens artísticas muito perfeitas. Justamente, um dos exemplos extraídos da pintura por Aristóteles conflacciona o reconhecimento de figuras humanas com a identificação de ethos na pintura por analogia com a representação de ethos na poesia: "As tragédias da maior parte dos poetas modernos não têm caracteres e o mesmo acontece com muitos poetas de um modo geral e assim também, entre os pintores, com Zêuxis em oposição a Polignoto: é que Polignoto é um bom pintor de caracteres, enquanto que a pintura de Zêuxis não tem nenhum carácter" (Po. 1450å25ff; Aristóteles volta a subvalorizar o realismo lendário das obras de Zêuxis, justamente pela mesma razão, Po. 1461b10ff). Esta leitura em nada obsta, porém, o ponto geral de Halliwell de que o prazer próprio da tragédia "nasce do exercício das nossas capacidades de entender coisas e sentir coisas quando nos relacionamos com as possibilidades imaginárias que a arte representa" ("Pleasure, Understanding and Emotion in Aristotle's Poetics", Essays on Aristotle's Poetics, ed. A.O, Rorty. Princeton University Press: New Jersey, 1992, p. 255-256). 
ideologia da catarse). Bastaria mencionar que uma reacção partilhada ocorre, isto é, que alguma coisa é partilhada por 'nós'. Por si só, isso é prova suficiente de que as pessoas partilham expectativas, mas também de que partilham expectativas em relação a certas coisas.

Será difícil não dar pelo 'nós' que paira sobre todo o argumento de Aristóteles, manifestando-se de vez em quando em referências correntes ao 'nosso espírito', a homens 'melhores que nós' e 'piores que nós', 'semelhantes a nós', ou simplesmente como nós. Quão semelhantes são, porém, tais criaturas, e que medida de semelhança é aqui a de Aristóteles? As suas transições demasiado rápidas entre uma acepção étnica e uma acepção universal (quer dizer, entre 'nós-qua-atenienses' por oposição a 'eles-qua-bárbaros' ${ }^{61}$ e 'nósqua-animais-assim-e-assim') parecem-nos hoje chocantes. Por alguma razão, Aristóteles mistura os dois sentidos, o que torna qualquer tentativa de os distinguir entre si numa tarefa ainda mais delicada. Começando pela última acepção, a universal, não nos surpreende sermos definidos como uma espécie racional, tal como nos é sugerido nas passagens já aludidas do capítulo 4 da Poética, nas quais Aristóteles conflaciona prazer e actividade inferencial, referindo-se ainda, numa glosa óbvia da abertura da Metafísica, a um desejo natural de aprender. Por outro lado, a mais clara qualificação da espécie feita por Aristóteles ainda no mesmo capítulo refere-se, antes, no entanto, a sermos os mais miméticos dos animais ("o homem é o que tem mais capacidade de imitar"). ${ }^{62}$ Aliás, é-nos explicado que é "pela imitação que [adquirimos] os nossos primeiros conhecimentos", ${ }^{63}$ como se a formação de logos fosse causada, i.e. explicada, em última análise, por um grau hiperdesenvolvido de capacidade mimética. (No início da Metafísica, Aristóteles esboça também um argumento paralelo a respeito do nosso grau desenvolvido de capacidade de memória. Capacidade mnemónica e capacidade mimética parecem andar de mãos dadas no reino Animalia.) Dizer que certas criaturas são racionais e dizê-las super miméticas está longe de constituir uma oposição entre duas definições mutuamente exclusivas. Pode ser, pelo contrário, que estas sejam duas hipóteses reciprocamente explicativas acerca da natureza de tais criaturas. Halliwell observa que a mesma hipótese a respeito de um elevado grau de capacidade mimética como critério adequado de explicação para as causas do 'entendimento' (logos) é também avançada por Pseudo-Aristóteles nos Problemas, cujo autor parece citar a Poética. É-nos ali sugerido que a 
razão pela qual devemos depositar mais confiança num ser humano do que em qualquer outro animal não é a de apenas os homens saberem fazer contas (como Platão sugerira a Néocles), nem a de que apenas eles acreditam em deuses, mas a de que são os mais miméticos de entre os animais, sendo isso "que lhes permite aprender e compreender" (956a11-14).

O mais extraordinário é talvez que Pseudo-Aristóteles sequer deposite alguma confiança noutros animais. Do seu ponto de vista, relações de confiança não se restringem então a animais dotados de capacidades aritméticas, mas são antes extensíveis, em menor grau, todavia, a criaturas sem deus, nem matemática (e, já agora, mais ou menos previsíveis e desprovidas de linguagem). Não pode é haver laços de confiança onde não houvesse antes expectativas, mesmo que estas tenham um aspecto muito básico. A 'mimese' (ou na verdade um grau elevado de capacidade mimética) parece ser, pois, o que salvaguarda e, em última análise, explica a própria possibilidade de se formar e partilhar expectativas mais complexas, tais como as que são requeridas pelo estabelecimento de laços de confiança mais fortes, mais complexos e mais duradouros, ainda que estes sejam muitas vezes largamente imperceptíveis e dados por adquiridos. Em Moral Prejudices, Annete Baier observa que "Habitamos um clima de confiança da mesma maneira que habitamos uma atmosfera", e que "damos por ela tal como damos pelo ar, apenas quando este se torna escasso ou poluído". ${ }^{4}$ Poderíamos talvez defender que a natureza hipermimética dos seres humanos é o que melhor explica a existência de comunidades de disposições, de que a 'atmosfera de confiança' de Baier é um exemplo perfeitamente adequado. Nesse caso, poderíamos ainda imaginar que o logos é relativo a modos de transformar um espaço de expectativas num espaço de razões, para usar a expressão de Sellars: i.e. modos de tornar explícita a existência de um ethos partilhado. Num sentido minimal, um ethos comum pode ser descrito como um conjunto de expectativas partilhadas. Todavia, tal concepção de ethos não faz sentido a não ser que pensemos numa comunidade (ethnos) que o partilha. Por outras palavras, presume-se alguma forma ou configuração social a que nos possamos referir através de expressões como, por exemplo, 'nós-como-atenienses', etc. Ao percebermos isto, o que antes parecia (na melhor das hipóteses) uma confusão gramatical insuperável, torna-se, de súbito, na razão de ser do plural étnico de Aristóteles. No fim de contas, o grau de mimeticidade nos seres humanos é em parte a condição necessária para que se estabeleçam justamente os tipos de laços requeridos 
para a formação, florescimento e durabilidade de comunidades humanas, comunidades que se moldam e organizam em função de expectativas mais ou menos parecidas. Assim, num sentido que a Poética ajuda a tornar claro, ou que uma poiêtikê technê ajuda a capturar, as reacções geradas em 'nós' por uma tragédia não são essencialmente aquilo a que chamamos um efeito puramente 'estético', mas antes de mais a expressão (evidentemente, explorada pelos poetas) de um ethos comum, de expectativas partilhadas por uma dada comunidade. Como observa Aristóteles: "os poetas orientam-se pelos espectadores e compõem de acordo com as suas preferências". ${ }^{65}$

Quero agora retomar por momentos a ideia de que a expectativa de uma apologia da poesia com a forma de uma teoria da catarse foi facilitada pelas atmosferas intelectuais nas quais decorreu o debate sobre a katharsis trágica ao longo dos últimos séculos. Uma boa objecção aos fins éticos tradicionalmente depositados numa 'estética' aristotélica (aliás, ironicamente platonista) é, no entanto, a de que tal projecto pecaria desde logo pela famosa falta de gosto de Aristóteles, a qual embaraça muitos dos seus leitores desde o Renascimento. Como explicar que das trinta e duas tragédias mencionadas por Aristóteles apenas duas sobrevivem, afinal, ao teste da catarse: o Rei Édipo e a Ifigénia entre os Tauros, de Eurípides? Historicamente e por razões pedagógicas inclinámo-nos tipicamente a tentar extrair da Poética um certo modelo de tragédia perfeita, e esse projecto tem dominado as nossas atenções desde que nos lembramos. Contudo, não deveríamos perder de vista o evidente fascínio de Aristóteles por uma enorme quantidade de exemplos de erros poéticos - e o facto de os considerar erros poéticos não precisa de ser tomado necessariamente como um sintoma de falta de gosto. Os seus elogios técnicos são decerto tão relevantes do ponto de vista filosófico (embora não, quem sabe, para a história da literatura) quanto as suas censuras. Por exemplo, esclarecer que "homens bons a passar da felicidade para a infelicidade (...) suscita repulsa, mas não temor nem piedade" ${ }^{66}$ é, sem dúvida, um modo tão adequado quanto qualquer outro para dar inteligibilidade, sob um vocabulário técnico racional, à forma como criaturas 'como nós' partilham disposições. Por outro lado, deslocarmos a discussão para fora do horizonte de expectativas habitual ajuda-nos, ainda, a entender o sentido em que a discussão anterior sobre o plural fantasma da Poética se relaciona com uma das observações mais misteriosas de Aristóteles, a saber, a de que "a ideia de correcção da política e da poética não é a mesma" ${ }^{67}$ 
No capítulo 25, onde discute erros técnicos e soluções para esses erros, Aristóteles vai testando diferentes fórmulas para a mesma ideia, nomeadamente que "escrever coisas impossíveis é errar; mas está correcto (...) se o objectivo próprio da arte for alcançado". ${ }^{68}$ Desde que o objectivo próprio da arte seja alcançado (i.e. representar acções de tal forma que se produza uma certa reacção partilhada), a verosimilhança pode bem ser sacrificada, ${ }^{69}$ erro a que não nos devemos nem podemos dar ao luxo em política. A implicação interessante é aqui a de que, apesar de tal licença poder levar os espectadores a reconhecer ou, antes, representar coisas "impossíveis" ou "irracionais" (um dos fortes de Homero, por exemplo), tal não constitui impedimento a uma reacção partilhada. Daqui se segue que não obstante a verdade, falsidade ou mesmo a irracionalidade daquilo que, dessa forma, é representado no nosso "espírito" ( $p$ suchê), tal reacção continua a denotar a presença (activa) de uma comunidade de emoções, disposições ou orientações para o mundo. Ora, descrever as causas técnicas de tal partilha de reacções (projecto a que certas partes da Retórica poderão dar um contributo valioso) é assim um modo de conferir inteligibilidade a um ethos comum - i.e. de o tornar explícito sob a descrição de um vocabulário técnico racional. Esta talvez seja a única função que a poiêtikê technê pode alguma vez ter procurado cumprir, mas é desnecessário fazer quaisquer conjecturas a esse respeito. Também se segue, por outro lado, seja como for, que um ethos comum pode bem ser erróneo e ao mesmo tempo ser a expressão de um facto do mundo. Que as expectativas partilhadas denotadas por uma reacção moral partilhada possam ser erróneas leva-nos a suspeitar da robustez do realismo moral normalmente imputado às posições assumidas por Aristóteles na Poética. Embora as suas salvaguardas a respeito de uma 'correcção poética' abram as portas à possibilidade algo remota de ilusões colectivas (por exemplo, o forte de Houdini), não há propriamente razão para fazermos soar um alarme monista. Para todos os efeitos, é justamente por a relação entre arte e pessoas não ser uma relação causal necessária (ou justamente por não haver aqui uma lei) que não nos devemos preocupar com tal coisa a que se pudesse chamar uma ilusão universal.

Por fim, não é de admirar que o género de cenas de reconhecimento a que Aristóteles concede prioridade técnica seja, como vimos, o reconhecimento com peripécia. ${ }^{70}$ Recordemos que a peripécia consiste na "mudança dos 
acontecimentos para o seu reverso, mas (...) de acordo com o princípio da verosimilhança e da necessidade", ${ }^{71}$ uma mudança nos acontecimentos que vai contra (ou num sentido especial, defrauda) as nossas expectativas normais sobre o mundo. Ao afirmar que os incidentes que causam "temor e compaixão (...) são muito [mais] facilmente suscitadas [ou causam muito mais impressão] quando se processam contra a nossa expectativa" e ao mesmo tempo "por uma relação de causalidade entre si", ${ }^{72}$ Aristóteles parece admitir, por um lado, que nunca esperamos que alguém seja o causador acidental da sua própria desgraça, e, por outro lado, que nos espanta sempre descobrir a fragilidade das nossas próprias expectativas. Aquilo que a poiêtikê technê permite revelar nesses casos é, então, não apenas que tínhamos expectativas (se quisermos: expectativas opacas), mas, para além disso, que mesmo tais expectativas opacas têm uma forma inerentemente racional, i.e. têm uma 'ordem natural', efeksês. ${ }^{73}$

\section{Referências bibliográficas}

ARISTÓTELES, The Complete Works of Aristotle. The Revised Oxford Translation, vol. 1 e 2, BARNES, J. (ed.), Princeton: Princeton University Press, 1995.

ARISTÓTELES, De Poetica, The Basic Works of Aristotle, trad. Bywater, ed. McKeon, Random House: New York, 1941.

ARISTÓTELES, Poética. VALENTE, A.M. (trad.), Lisboa: FCG, 2004.

ARISTÓTELES, Retórica. ALBERTO, P.F., JÚNIOR, M.A., PENA, A.N. (trad.), Lisboa: INCM, 2005.

BAIER, A. Moral Prejudices, Harvard University Press: Cambridge Massachusetts, 1995, p. 98.

BELFIORE, E. Tragic Pleasures: Aristotle on Plot and Emotion, Princeton University Press: Princeton, 1992.

BELFIORE, E. "Aristotle on Tragic and Comic Mimesis", Bryn Mawr Classical Review, http://ccat.sas.upenn.edu/bmcr/1993/04.01.12.html, 2004.

BRITO, H. Pessoas como Nós: Uma discussão da Poética de Aristóteles, dissertação de doutoramento, Universidade de Lisboa, Lisboa, 2007, http://www.fl.ul.pt/ posgraduados/teoria literatura/Brito2.pdf

ELSE, G. Aristotle's Poetics: the Argument, Cambridge: Harvard University Press, 1957.

GOLDEN, L. "Catharsis", TPAPA, vol. 93, 1962, pp. 51-60. 
GOLDEN, L. "Mimesis and Katharsis", Classical Philology, vol. 64, No. 3, 1969, pp. 145-153.

GOLDEN, L. "The Purgation Theory of Catharsis", The Journal of Aesthetics and Art Criticism, Vol. 31, No. 4, 1973, p. 473.

GOLDEN, L. "The Clarification Theory of Catharsis", Hermes, 104, 1976, pp. 43752.

GOLDEN, L. "Katharsis as Clarification: An Objection Answered", The Classical Quarterly, New Series, vol. 23, No. 1, 1973.

GOLDEN, L. "Toward a Definition of Tragedy", The Classical Journal, vol. 72, No. $1,1972$.

HALLIWELL, "Aristotelian Mimesis and Human Understanding”, S. Ø. Andersen and J. Haarberg (ed.), Making Sense of Aristotle: Essays in Poetics, London: Duckworth, 2001.

HALLIWELL, S. "Pleasure, Understanding and Emotion in Aristotle's Poetics", Essays on Aristotle's Poetics, ed. A.O, Rorty. Princeton University Press: New Jersey, 1992, p. 255-256.

HALLIWELL, The Aesthetics of Mimesis, Ancient Texts and Modern Problems, 2002. JAVITCH, D. "On the Rise of Genre specific Poetics in the Sixteenth Century" (2001), $\varnothing$. Andersen and J. Haarberg (ed.), Making Sense of Aristotle: Essays in Poetics, London: Duckworth, 2001.

LEAR, J. "Catharsis", Essays on Aristotle's Poetics, ed. A.O, Rorty. Princeton University Press: New Jersey, 1992.

LESSING, Hamburgische Dramaturgie (1767), Dramaturgia de Hamburgo, Selecção Antológica, trad. de Manuela Nunes, Fundação Calouste Gulbenkian, Lisboa, 2005. MACINTYRE, A. After Virtue, A study in moral theory (1985), Duckworth: Londres, 2003.

NUSSBAUM, M. The Fragility of Goodness: Luck and Tragedy on Greek Tragedy and Philosophy, 1986, Cambridge: Cambridge University Press, 2001.

WEINBERG, A History of Literary Criticism in the Italian Renaissance, vol. I, Chicago: University of Chicago Press, 1961. 